\title{
PENERAPAN ALGORITMA C4.5 UNTUK KLASIFIKASI STATUS KESEJAHTERAAN RUMAH TANGGA KELUARGA BINAAN SOSIAL DI KABUPATEN BULUKUMBA
}

\author{
Mansyur $^{1}$, Yuyun $^{2}$, Rabiatul Adawiyah ${ }^{3}$ \\ Program Studi Keamanan Sistem informasi,Politeknik Nusantara makassar, Indonesia ${ }^{1}$ \\ Program Studi Sistem Komputer, STMIK Handayani Makassar, Indonesia ${ }^{2}$ \\ Manajemen Pendidikan Islam, Universitas Muhammadiyah Jakarta, Indonesia ${ }^{3}$ \\ Email : mansyurmantari@gmail.com ${ }^{1}$, yuyunwabula@handayani.ac.id², \\ wiyahdpr@gmail.com ${ }^{3)}$
}

\begin{abstract}
ABSTRAK
Kemiskinan merupakan salah satu permasalahan dalam upaya peningkatan kesejahteraan di semua daerah. Dengan mengetahui status kesejateraan, memudahkan dalam pengelompokanya. Penelitian ini bertujuan untuk mengklasifikasi status kesejahteran Rumah Tangga, dikabupaten Bulukumba menggunakan algoritma C4.5. Dalam penelitian ini, kami menggunakan 10 (sepuluh) atribut yang terdiri dari jenis kelamin, umur, status tempat tinggal, jumlah anggota keluarga, lapangan usaha, jumlah atap terluas, jenis dinding, jenis lantai, sumber air minum, dan sumber penerangan. Dari hasil analisis, ditemukan 18 (delapan belas) pola untuk menidentifikasi status kesejateraan keluarga. Dariperhitungan algoritma C.45 diperole sumber air minum adalah indikator utama untuk mengukur tingkat kesejahteraan masyarakat dengan nilai gain tertinggi 0.322 . Kemudian nilai gain terendah terdapat pada atribut usia dengan nilai 0.001 .
\end{abstract}

Kata Kunci : Kesejahteraan; Klasifikasi; C.45

\begin{abstract}
Poverty is one of the problems in efforts to improve welfare in all regions. By knowing the status of welfare, it is easy to group them. This study aims to classify the welfare status of Households, Bulukumba Regency using the C4.5 algorithm. In this study, we use 10 (ten) attributes which consist of gender, age, residence status, number of family members, business fields, the largest number of roofs, wall types, floor types, drinking water sources, and lighting sources. From the analysis results, 18 (eighteen) patterns were found to identify family welfare status. Then, from analysis of the C.45 algorithm, it found that the source of drinking water is the main indicator to measure the level of community welfare with gain 0.322. Then the lowest gain is age attribute with value 0.001 .
\end{abstract}

Keywords: Welfare; Classification; C.45 


\section{PENDAHULUAN}

Sesuai dengan Undang- undang RI No 13 Tahun 2011 tentang penanganan fakir miskin dilaksanakan secara terarah, terpadu dan berkelanjutan oleh pemerintah. Saat ini kemiskinan telah menjadi masalah yang harus ditanggulangi secara tuntas sebagaimana diamanatkan dalam Pembukaan UndangUndang Dasar 1945 ( Jurnal Jendela Hukum, n.d.). Ketersedian data kemiskinan yang akurat, dan berkesinambungan adalah salah satu instrumen penting untuk pengambilan keputusan dalam mendistribusikan bantuan Rumah Tangga Sasaran (RTS) (Buku Menjangkau Masyarakat Miskin dan Rentan.). Salah satu upaya pemerintah memberantas kemiskinan di Indonesia yaitu dengan meluncurkan Program Peningkatan Kualitas Permukiman (P2KP)(Sukidjo, 2005). kemudian menjadi Program Nasional Pemberdayaan Masyarakat Perdesaan(PNPM-Pd) (Murbeng \& Soeaidy, n.d.), atau yang saat ini menjadi Dana desa (Meutia \& Liliana, 2017). Sejak tahun 2007 Pemerintah Indonesia telah melaksanakan Program Keluarga Harapan (PKH) yang dinaungi kementrian sosial yang dikenal dengan istilah Conditional Cash Transfers $(C C T)$. Program Keluarga Harapan tersebut terbukti cukup berhasil dalam menanggulangi kemiskinan di dunia, terutama masalah kemiskinan kronis(Profil program keluarga harapan (PKH), 2009).

Di kabupaten Bulukumba saat ini sebanyak 13.716 kepala keluarga penerima bantuan sosial dari Program Keluarga Harapan (PKH). Permasalah dalam pengelolaan data ini masih dilakukan secara manual dalam penentuan status kesejahteraan masyarakat yang layak mendapatkan bantuan. Sehingga diperlukan cara untuk mengklasifikasi status kesejahteraan rumah tangga menggunakan variable target/kelas berupa kategori hampir miskin, miskin dan sangat miskin. Sehingga dengan demikian pendistribuasian bantuan tepat dapat disesuaikan dengan status kesejahteraan setiap keluarga.

Penelitian tentang penentuan kesejahteraan keluarga telah dilakukan beberapa peneliti yaitu Klasifikasi Kesejahtraan Rumah Tangga dengan Penerapan Algoritma Decision Tree menggunakan kriteria miskin dan hampir miski. Penerapan Algoritma Naive Bayes Untuk Klasifikasi Status Kesejahteraan Rumah Tangga Keluarga Binaan Sosial dalam penelitian tersebut masih menggunakan dua variabel yaitu miskin dan sangat miskin, sehingga kami mengembangkan saran peneliti sebelumnya untuk menambahkan variabel hampir miskin.

Tujuan penelitian ini adalah untuk mengkalsifikasi status kesejahteraan rumah tangga keluarga binaan sosial di Kabupaten Bulukumba. Studi ini akan mengelompokan masyarakat yang layak mendapatkan bantuan menggunakan algoritma C.45. Untuk menguji hasil akurasi penerima bantuan menggunkan precision, recall dan acurasi

\section{LANDASAN TEORI}

Penelitian dengan penelitian Klasifikasi Status Kesejahteraan Rumah Tangga Keluarga Binaan Sosial berbasis 
Seleksi Atribut Chi Squared. Selain itu dalam penelitian lain (Husnul, 2017) menggunkan Metode Quest Dalam Pembentukan dalam Klasifikasi Tingkat Kemiskinan Rumah Tangga Studi Kasus: Rumah Tangga Di Kota Padang. Selain itu, (Agustina et al., 2017) mengklasifikasi Tingkat Kesejahteraan Keluarga Menggunakan Metode Regresi Logistik Ordinal Dan Support Vector Machine (Svm). Dalam penelitian, kami mengusulkan Algoritma C.45 dalam penentuan status kesejahteraan rumah tangga dengan variabel jenis kelamin, umur, status tempat tinggal, jumlah anggota keluarga, lapangan usaha, jenis atap terluas, dinding terluas, jenis lantai, sumber air minum dan sumber penerangan. atribut sumber air minum adalah kriteria utama untuk menentukan tingkat kejejahteraan.

\section{METODE PENELITIAN}

3.1. Pengumpulan Data

Data yang telah dikumpulkan sebanyak 13.716 Kepala Keluarga, merupakan data sekunder dari penerima bantuan sosial Program Keluarga Harapan (PKH) Kabupaten bulukumba tahap II tahun 2019. Pengolahan data dengan menggunakan algoritma c4.5 yang diola dengan Microsoft excel

\subsection{Algoritma $\mathrm{C} 4.5$}

Algoritma c4.5, dilakukan perhitungan untuk mencari nilai entrophy dan gain. Entrophi merupakan jumlah bit yang diperkirakan dibutuhkan untuk dapat mengekstrak suatu kelas (+ atau -) dari sejumlah data acak pada ruang sampel $\mathrm{S}$ berikut rumus untuk mencari nilai entrophy, sebagai berikut:

$$
\operatorname{Entrophy}(\mathrm{S})=\sum_{\mathrm{j}=1}^{\mathrm{k}}-\mathrm{pj} \log _{2} \mathrm{pj}
$$

Keterangan :

$\mathrm{S}$ : Himpunan kasus

k : Jumlah partisi S

pj : Jumlah kasus pada partisi ke-j

Sedangkan Gain merupakan perolehan informasi dari atribut A relative terhadap output data S. Perolehan informasi didapat dari output data atau variabel depedent $S$ yang dikelompokkan berdasarkan atribut A, dinotasikan dengan Gain (S,A). Rumus untuk mencari nilai gain, sebagai berikut :

$\operatorname{Gain}(\mathrm{A})=$ Entrophy $(\mathrm{S})-\sum_{\mathrm{j}=1}^{\mathrm{k}} \frac{\mathrm{Si}}{\mathrm{S}} *$ Entrophy (Si)

Keterangan :

$\begin{array}{ll}\text { A } & \text { : Atribut dari dataset } \\ \mathrm{k} & \text { : Jumlah partisi S } \\ \mathrm{S} & \text { : Himpunan Kasus }\end{array}$

\section{HASIL DAN PEMBAHASAN}

4.1 Pengolahan Data

Pada tabel 1 berikut diuraikan secara rinci dari hasil perhitungan Entrophy dan Gain dengan menggunakan excel. Dari perhitungan yang telah dilakukan untuk mencari nilai gain dari masing-masing variabel, maka didapatkan nilai gain tertinggi terdapat pada variabel sumber air minum dengan nilai gain sebesar 0.322 selanjutnya akan dibuat percabangan pohon keputusan dari gain tertinggii. Adapun cabang yang terbentuk, Pada Gambar 1 : 
Tabel 1. Hasil Perhitungan Entrophy Dan Gain Dengan Menggunakan Excel

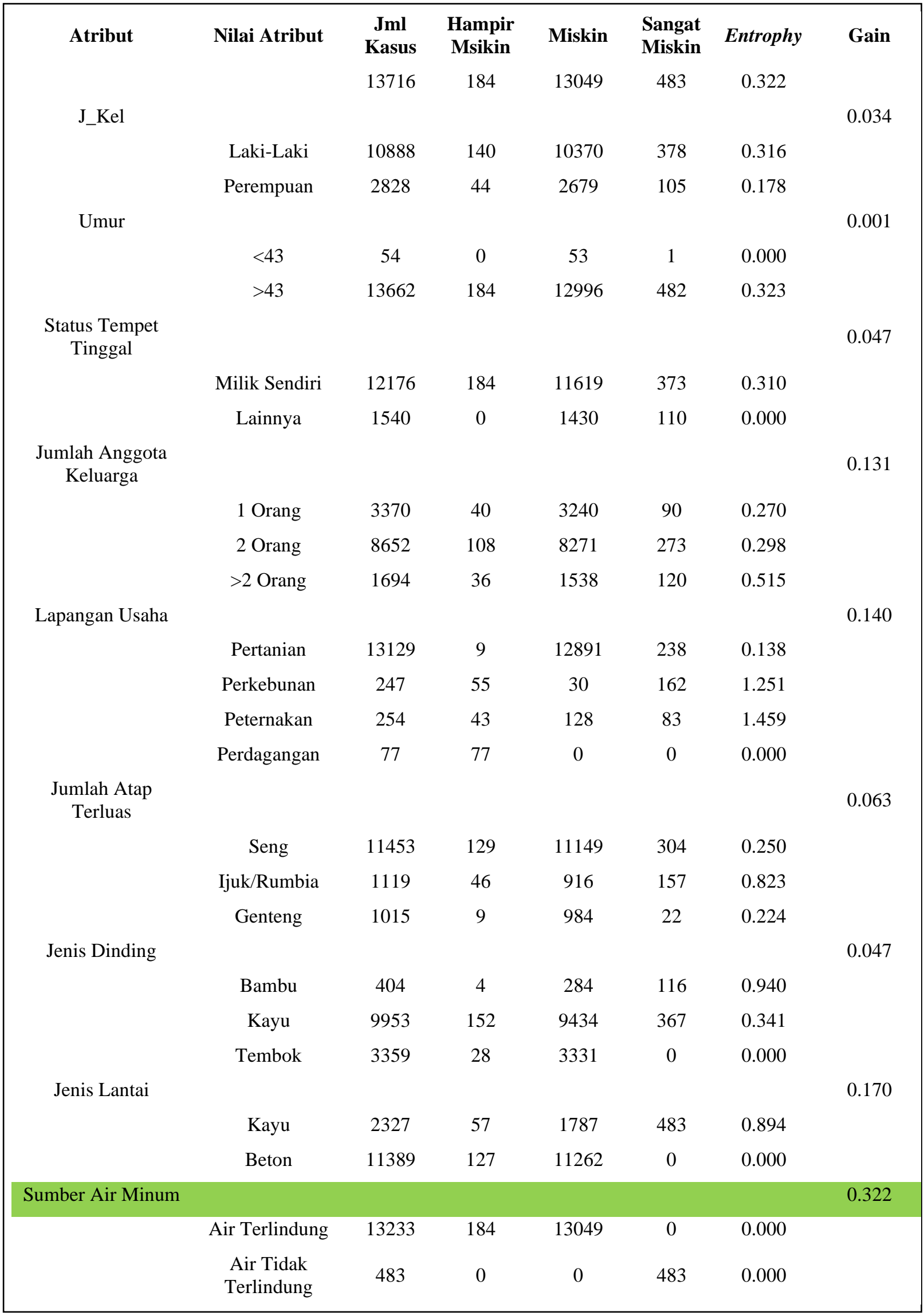




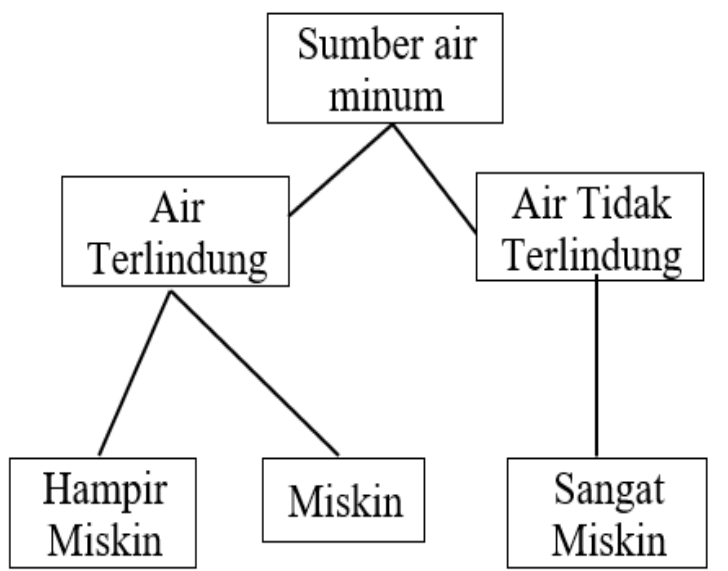

Gambar 1. Pohon Keputusan

Pada pohon keputusan yang terbentuk dapat disimpulkan, variabel sumber air minum untuk air tidak terlindung hanya digunakan oleh status keluarga sangat miskin dan air terlindung digunakan oleh masyarakat yang berstatus hampir miskin dan miskin.

\subsection{Pengujian Precision, Recall dan Akurasi}

Pengujian Algoritma C.45 juga dilakukan dengan menggunakan data testing senyak 55 (lima puluh lima) record dari 18 Rules Penentuan Status Kesejahteraan Warga, dengan melihat hasil perhitungan Entrophy dan Gain pada data training serta hasil percabangan atau pohon keputusan yang telah dibuat. Proses pengujian juga dilakukan dengan menghitung nilai precision, recall dan accuracy.

Tabel 2. Aturan Penentuan Status Kesejahteraan Warga

\begin{tabular}{ccccc}
\hline No & Kelamin & Umur & Status Tempat Tinggal & $\begin{array}{c}\text { Jum Anggota } \\
\text { Keluarga }\end{array}$ \\
\hline 1 & Pria & $>43$ & Lainnya & $>2$ Orang \\
2 & Wanita & $>43$ & Milik Sendiri & 1 Orang \\
3 & Pria & $<43$ & Milik Sendiri & 2 Orang \\
4 & Pria & $>43$ & Lainnya & 2 Orang \\
5 & Wanita & $>43$ & Milik Sendiri & 2 Orang \\
6 & Pria & $<43$ & Milik Sendiri & 1 Orang \\
7 & Pria & $<43$ & Milik Sendiri & 2 Orang \\
8 & Pria & $>43$ & Lainnya & 2 Orang \\
9 & Wanita & $>43$ & Milik Sendiri & 2 Orang \\
10 & Pria & $>43$ & Milik Sendiri & $>2$ Orang \\
11 & Wanita & $>43$ & Lainnya & 1 Orang \\
12 & Pria & $<43$ & Milik Sendiri & 1 Orang \\
13 & Pria & $>43$ & Milik Sendiri & 2 Orang \\
14 & Pria & $>43$ & Lainnya & $>2$ Orang \\
15 & Wanita & $<43$ & Lainnya & 2 Orang \\
16 & Pria & $>43$ & Lainnya & $>2$ Orang \\
17 & Wanita & $>43$ & Milik Sendiri & 2 Orang \\
18 & pria & $<43$ & Lainnya & 1 Orang \\
\hline & & &
\end{tabular}


Tabel 3. Lanjutan Aturan Penentuan Status Kesejahteraan Warga

\begin{tabular}{ccccc}
\hline No & Lapangan usaha & Jenis atap terluas & $\begin{array}{c}\text { Jenis } \\
\text { dinding } \\
\text { terluas }\end{array}$ & $\begin{array}{c}\text { Jenis } \\
\text { lantai }\end{array}$ \\
\hline 1 & Pertanian & Ijuk / Rumbia & Kayu & Kayu \\
2 & Pertanian & Seng & Tembok & Beton \\
3 & Pertanian & Seng & Kayu & Kayu \\
4 & Peternakan & Seng & Kayu & Beton \\
5 & Perdagangan & Seng & Kayu & Beton \\
6 & Pertanian & Ijuk / Rumbia & Bambu & Kayu \\
7 & Perdagangan & Ijuk / Rumbia & Kayu & Kayu \\
8 & Pertanian & Ijuk / Rumbia & Bambu & Kayu \\
9 & Perdagangan & Seng & Kayu & Beton \\
10 & Pertanian & Ijuk / Rumbia & Bambu & Kayu \\
11 & Pertanian & Seng & Kayu & Kayu \\
12 & Pertanian & Seng & Bambu & Kayu \\
13 & Perdagangan & Ijuk / Rumbia & Kayu & Beton \\
14 & Pertanian & Genteng & Bambu & Kayu \\
15 & Perkebunan & Seng & Kayu & Kayu \\
16 & Perkebunan & Genteng & Tembok & Beton \\
17 & Perdagangan & Seng & Bambu & Beton \\
18 & Perkebunan & Seng & Kayu & Kayu \\
\hline
\end{tabular}

Tabel 4. Lanjutan Aturan Penentuan Status Kesejahteraan Warga

\begin{tabular}{cccc}
\hline No & $\begin{array}{c}\text { Sumber } \\
\text { air minum }\end{array}$ & $\begin{array}{c}\text { Sumber } \\
\text { penerangan }\end{array}$ & Ket \\
\hline 1 & Air Tidak Terlindung & Tidak Ada Listrik & Sangat Miskin \\
Miskin \\
2 & Air Terlindung & Listrik PLN & Sangat Miskin \\
3 & Air Tidak Terlindung & Tidak Ada Listrik & Miskin \\
4 & Air Terlindung & Listrik PLN & Hampir Miskin \\
5 & Air Terlindung & Listrik PLN & Sangat Miskin \\
6 & Air Tidak Terlindung & Tidak Ada Listrik & Hampir Miskin \\
7 & Air Terlindung & Listrik PLN & Miskin \\
8 & Air Terlindung & Tidak Ada Listrik & Hampir Miskin \\
9 & Air Terlindung & Listrik PLN & Sangat Miskin \\
10 & Air Tidak Terlindung & Tidak Ada Listrik & Miskin \\
11 & Air Terlindung & Listrik PLN & Miskin \\
12 & Air Terlindung & Tidak Ada Listrik & Miskin \\
13 & Air Terlindung & Tidak Ada Listrik & Miskin \\
14 & Air Terlindung & Listrik PLN & Miskin \\
15 & Air Terlindung & Tidak Ada Listrik & Sangat Miskin \\
16 & Air Tidak Terlindung & Listrik PLN & Hampir Miskin \\
17 & Air Terlindung & Tidak Ada Listrik & Miskin \\
18 & Air Terlindung & Listrik PLN &
\end{tabular}


Rumus :

$$
\begin{aligned}
\text { Precision } & =\frac{T P}{T P+F P} \\
\text { Recall } & =\frac{T P}{T P+F N} \\
\text { Accuracy } & =\frac{T P+T N}{T P+F P+T N+F N}
\end{aligned}
$$

Keterangan :

$$
\begin{array}{ll}
\text { TP } & : \text { True Positif } \\
\text { TN } & : \text { True Negatif } \\
\text { FP } & : \text { False Positif } \\
\text { FN } & : \text { False Negatif }
\end{array}
$$

Diketahui :

$$
\begin{array}{ll}
\text { TP } & : 11 \text { (Miskin) }+23 \text { (Hampir Miskin) } \\
& =34 \text { orang } \\
\text { TN } & : 15 \text { (Sangat Miskin) } \\
\text { FP } & : 0 \text { orang } \\
\text { FN } & : 6 \text { orang }
\end{array}
$$

Penyelesaian:

\section{Precision}

$$
\text { Precision }=\frac{34}{34+0} \times 100=100 \%
$$

$$
\begin{aligned}
& \text { Nilai Recall } \\
& \text { Recall }=\frac{34}{34+6} \times 100=85 \%
\end{aligned}
$$

\section{Nilai Accuracy}

$$
\text { Accuracy }=\frac{34+15}{34+0+15+6} \times 100=89 \%
$$

Dari perhitungan di atas dengan menggunakan 55 data testing, menghasilkan nilai precision sebesar $100 \%$, nilai recall $85 \%$ dan nilai accuracy sebesar $89 \%$

\section{SIMPULAN DAN SARAN}

\subsection{Simpulan}

Berdasarkan hasil penelitian dapat disimpulan sebagai berikut:
1) Nilai gain tertinggi terdapat pada atribut sumber air minum dengan gain 0.322 . Ini berarti atribut sumber air minum adalah kriteria utama untuk menentukan tingkat kejejahteraan. Sementara itu nilai gain terendah terdapat pada atribut usia dengan nilai 0.001 .

2) Dari hasil simulasi lima puluh lima (55) record data testing, terdapat 6 (enam) data yang tidak sesuai dengan hasil prediksi. Data yang seharusnya hampir miskin dalam hitungan manual menjadi sangat miskin dalam hitungan sistim. Ini karena nilai atribut lapangan usaha perdagangan bertemu dengan atribut sumber air minum

3) Dari hasil perhitungan dengan menggunakan 55 (lima puluh lima) data testing, menghasilkan nilai precision sebesar $100 \%$, nilai recall $85 \%$ dan nilai accuracy sebesar $89 \%$

\subsection{Saran}

Pada penelitian ini, peneliti hanya menggunakan tiga variabel yaitu hampir miskin, miskin dan sangat miskin dengan sepuluh atribut diharapkan pada penelitian selanjutnya menambahkan atribut jumlah penghasilan, bahan bakar masak, cara memperoleh air minum, status lahan tempat tinggal

\section{DAFTAR PUSTAKA}

Agustina, S., Agoestanto, A., \& Hendikawati, P. (2017). Klasifikasi Tingkat Kesejahteraan Keluarga Provinsi Jawa Tengah Tahun 2015 Menggunakan Metode Regresi Logistik Ordinal Dan Support Vector Machine. Unnes Journal of Mathematics, 6(1), 59-69. https://doi.org/10.15294/ujm.v6i1.1 1678 
Husnul, F. (2017). Penerapan Metode QUEST dalam Pembentukan Pohon Klasifikasi Tingkat Kemiskinan Rumah Tangga (Studi Kasus: Rumah Tangga di Kota Padang) [Diploma, Universitas Andalas]. http://scholar.unand.ac.id/22493/

Meutia, I., \& Liliana, L. (2017). Pengelolaan Keuangan Dana Desa. Jurnal Akuntansi Multiparadigma, 8(2), 336-352. https://doi.org/10.18202/jamal.2017. 08.7058

Murbeng, S. B., \& Soeaidy, M. S. (n.d.). Pelaksanaan Program Nasional Pemberdayaan Masyarakat Mandiri Perdesaan ( Pnpm Mp ) ( Studi pada Desa Bendungan Kecamatan Gondang Kabupaten Tulungagung ). 9.

Parker, S. W., \& Todd, P. E. (2017). Conditional cash transfers: The case of progresa/oportunidades. Journal of Economic Literature. https://doi.org/10.1257/jel.20151233
Pengentasan Kemisknan Di Tinjau Dari Undang-Undang Nomor 13 Tahun 2009 Tentang Penanganan Fakir Miskin Di Kabupaten Sumenep | Jurnal Jendela Hukum. (n.d.). Retrieved March 15, 2020, from https://www.ejournalwiraraja.com/i ndex.php/FH/article/view/447

Profil program keluarga harapan (PKH). (2009). Direktorat Jaminan Kesejahteraan Sosial, Direktorat Jenderal Bantuan dan Jaminan Sosial, Departemen Sosial RI.

Sukidjo, -. (2005). P2KP Sebagai Sarana Pemberdayaan untuk Pengentasan Kemiskinan. Jurnal Ekonomi dan Pendidikan, 2(1), Article 1. https://doi.org/10.21831/jep.v2i1.65 1

Tim Nasional Percepatan Penanggulangan Kemiskinan (2014), Buku Menjangkau Masyarakat Miskin dan Rentan. Jakarta 